\title{
The Relationship between Awareness Raising Activities and Students' proficiency in Reading Comprehension of Culturally- Bound Materials
}

Davud Kuhi

Islamic Azad University, Maragheh Branch, Maragheh, Iran

Mehrzad Hosseini Asl

Islamic Azad University, Maragheh Branch, Maragheh, Iran

Mahin Yavari

Islamic Azad University, Maragheh Branch, Maragheh, Iran Mahin.yavari@gmail.com

\section{Doi:10.5901/mjss.2013.v4n3p515}

\begin{abstract}
Comprehending a foreign language text, especially with unfamiliar words, is difficult. In order to understand a text, therefore, readers should have enough background knowledge. Cultural awareness is one of the important types of background knowledge. Reading and understanding a text isn't just due to teaching syntactic structures or teaching new vocabularies and expressions, but mainly incorporates, some cultural elements, which are intertwined with language itself. The present study, therefore, is an attempt to determine the effect of awareness raising activities on the reading comprehension of culturallybound materials. To this end, an experimental study was used. Participants were thirty students which were selected randomly and all were from English Language Teaching Department of Daneshvaran University in Tabriz. They were divided into two groups, one control group ( $n=15)$ and experimental group $(n=15)$. Before treatment, in order to assess their knowledge of reading comprehension, a proficiency test was given to both groups. During the treatment, the experimental group received cultural awareness before reading, but control group didn't receive any awareness. T-test also was used to measure the effect of awareness raising activities on the student's reading comprehension. The results of the post-tests of two groups indicated that awareness raising activities facilitate reading comprehension of culturally-bound materials. In fact, the experimental group achieved considerable success in reading comprehension than control group.
\end{abstract}

Keywords: awareness raising, culture, cultural awareness, linguistic awareness, prior knowledge, reading comprehension, schema theory

\section{Introduction}

Reading can be seen as an interactive process between a reader and a text. In this process, the reader interacts dynamically with the text as she/he tries to elicit the meaning and where various kinds of knowledge are being used: linguistic or systematic knowledge (through bottom-up processing) as well as schematic knowledge (through top-down processing). It is also considered as a complex cognitive and social process. Chastain (1988) believes that reading is the ability of swapping information from one person to another one. In his idea, reading is a respective skill in that reader receives a message from a writer and tries to decode it. The reading goal is to read for meaning or to recreate the writer's meaning. So, under these both reading purposes, it is possible to say that reading is "the process of receiving and interpreting information encoded in language form via the medium of print" (Urquhart \& Weir, 1998, p.22).

The common problem that students face with in reading classes is the comprehension of texts which are loaded with cultural terms. For most of them comprehending a text with new words and an unknown topic is difficult. The purpose of the present study was the elaborations on the benefits of awareness raising activities on the L2 learner's comprehension of cultural texts. Findings gave some insights about comprehension of cultural texts by developing awareness raising activities.

This study is of significance as reading not only forms a basic component of communicating with other people in their native language but naturally plays a crucial role in developing second/foreign language learning or acquisition 
(Rivers, 1981). It is, therefore, considerable that the role of conscious and unconscious processes and the notion of awareness rising in second language (L2) development in general and in the comprehension of culturally-bound material are very important. Some words and expressions have significations in a particular cultural context and without doing awareness raising activities to make the meaning of those expressions clear, misunderstandings will happen to learners. So, in order to eliminate these misunderstandings, what is needed, is providing awareness raising activities on the comprehension of culturally-bound texts.

\section{Literature Review}

\subsection{What is Culture?}

Up to now, there have been many definitions of "culture". It can be defined as what makes you a stranger when you are away from home. It includes all those beliefs and expectations about how people should speak and act which have become a kind of second nature to you as a result of social learning. When you are with members of a group who share your culture, you do not have to think about it, you are all viewing the world in pretty much the same way and you all know, in general terms, what to expect of one another. According to Kramsch, "culture can be defined as membership in a discourse community that shares a common social space and history, and common imaginings. Even when they have left that community, its members may retain, wherever they are, a common system of standards for perceiving, believing, evaluating and acting." (1998, p.10).

What is obvious is that language is a system of signs by their cultural value. Speakers identify themselves and others through their use of language; they view their language as a symbol of their social identity. Thus we can say that language symbolizes cultural reality and through all its verbal and non-verbal aspects, language embodies cultural reality, i.e. words reflect their authors' attitudes and beliefs, their points of view, which are also those of others. In other words, language expresses cultural reality. It is the principal means whereby we conduct our social lives. It is a complex collection of experiences which condition our daily life; it includes history, social structure, religion, traditional customs, and every day usage.

\subsection{What is Awareness raising?}

Awareness is the ability to perceive, to feel, or to be conscious of events, objects or sensory patterns. In this level of consciousness, sense data can be confirmed by an observer, without necessarily implying understanding. More broadly, it is the state or quality of being aware of something. The term "language awareness" (LA) is often used in discussions of second language acquisition (SLA) and foreign language teaching (FLT). This concept is very important in language education. LA is a broader and more sociocultural concept which originally started with the British Language Awareness Movement in the 1980's. In the U.K., it was found that pupils who had problems with learning English also had problems with learning a foreign language, and they recognized that teachers of English as a mother tongue and foreign language teachers should share their problems with each other and try to find common solutions. In 1982, the National Council for Language in Education (NCLE) defined LA as "a person's sensitivity and conscious awareness of the nature of language and its role in human life," and set three broad parameters-a cognitive parameter, an affective parameter, and a social parameter-to develop such sensitivity and awareness.

According to Wolfram (1998) formal instruction such as a language lesson, only develops explicit knowledge of language. However, after the learner has explicit knowledge about a language point, her/his consciousness of the new point has been raised. In fact she could be aware of the new point after the lesson. This type of awareness resulting from formal instruction has been called "consciousness-raising" in psycholinguistic theory (Ellis, 1993). Kohonen (1991) believes that in order to choose appropriate ways of raising student's awareness we should consider language learning as learner development in three interrelated areas.

A. Personal awareness: self-concept, self-esteem and self-direction;

B. Awareness of the learning process: process management

C. Task awareness: knowledge of language and communication.

Awareness is important because it appears to be a trigger initiating the restricting of the learner's implicit knowledge system. When a learner notices a language and culture point frequently, he/she unconsciously compares it with his/her existing system of linguistic and cultural knowledge, making new hypotheses to accommodate the differences between the noticed information and her current system. Again, all these new hypotheses are tested unconsciously by 
attending to language input and also by getting feedback on the output using the new form. In this form, implicit knowledge has been created. It is important to point that, due to the nature of the restricting process, the learner begins to produce the new form after a delay. So awareness tasks are necessary because they cause learners to notice not only the new form, but also its behavior (contrasting it with this of the L1).

Readers, when engaged in reading, are believed to go through an active and interactive process. Such a process presumes that readers have or should have some background knowledge about the topic of the text. The meaning of the text is not found in the material itself, but in the interaction that takes place between the reader and the text (Twist et al., 2004). Clearly, crucial to text comprehension is the reader's ability to organize information and relate new knowledge to the knowledge the reader already possesses. In fact readers maximize their comprehension by activating their schemata. Students' reading can be improved by helping them build background knowledge on the topic prior to reading, through appropriate reading activities. Taglieber et al. (1988) suggest that teacher use pre-reading activities such as pictorial context, field trips, demonstrations, debates and plays to activate appropriate knowledge structure and facilitate students' comprehension. Similarly, Carrell (1984) suggests pre-reading activities such as text previewing, pre-teaching unfamiliar vocabulary, and providing pre-reading questions for EFL students.

\subsection{Related Studies}

Steffensen and Joag-Dev (1984) conducted a study using two descriptions of weddings both written in English found that readers comprehended texts about their own cultures more accurately than the other. While the readers indicated that the words were easy to understand, the unfamiliar cultural protocol of an Indian wedding made the passage more difficult to remember. Sasaki (2000) investigated how schemata activated by culturally familiar words might have influenced students' cloze test-taking processes. Two groups of Japanese EFL learners with equivalent English reading proficiency completed either a culturally familiar or an unfamiliar version of a cloze test. Results demonstrated that those who read the culturally familiar cloze text tried to solve more items and generally understood the text better, which resulted in better performance, than those students who read the original text. In an another study, Pulido (2004) examined the effects of cultural background knowledge on immediate incidental vocabulary gain through reading brief narratives that depicted either culturally familiar or culturally unfamiliar versions of everyday scenarios. Participants were high-intermediate adult learners of Spanish. Each narrative contained 5 nonsense words depicting concepts frequently associated with the scenarios. Results of an ANCOVA revealed significant effects of cultural familiarity whereby vocabulary gains were greater after participants read within the culturally familiar versions of the scenarios. Also Erten \& Razi (2009) investigated whether cultural familiarity influences comprehension of short stories and whether nativizing the story or using reading activities can compensate for the lack of such familiarity. The analysis of variance indicated a better comprehension of the nativized story. Also, Alptekin (2006) investigated the role of cultural nativization in both literal and inferential comprehension of American short stories. Two groups of Turkish advanced EFL students read either the original version of an American short story or a nativized version, textually and contextually modified to reflect the learners' own culture. Then they answered multiple-choice comprehension questions aimed at checking inferential and literal comprehension independently across the two versions of the story. The results indicated that the nativization of a short story from the target language culture facilitates L2 readers' inferential comprehension significantly, yet it does not affect their literal comprehension. Following these studies, Jalilifar \& Assi (2008) in another study explored the role of cultural nativization in reading comprehension of target language short stories in Iranian EFL learners. For this end, 3 American short stories were nativized into learners' own culture (i.e. Persian) then, 2 types of reading comprehension tests, one based on the original stories and one based on the nativized versions, were developed. To carry out the research, 2 groups of advanced EFL learners, including 29 males and 31 females, participated in the study. In order to collect the relevant data, each version of the reading comprehension test was administered to one group of the subjects. The results clearly illustrated that cultural nativization had a facilitative effect on comprehension of the stories. Surprisingly, this effect was not only at the literal but also at the inferential level of comprehension.

Unfortunately, all of these studies are of limited use for several reasons. First of all, the studies aren't comparable due to variations in focus and in the conditions operationalized. Also the level of noticing in such studies may have been affected by variables including the level of language ability of research subjects, the complexity of information being processed, and the speed or audibility of presentation which casts doubt on the reliability of the findings. Another important fact is that noticing and awareness are internal process and can't be observed directly, but require a high degree of inference from observation of behavior. 
The major aim of this study was to investigate the effect of awareness raising activities on the reading comprehension of culturally bound texts. The present research addressed the following question:

Do awareness raising activities facilitate reading comprehension of culturally bound materials in L2 classrooms?

\section{Method}

\subsection{Participants}

The population of the present study comprised 50 EFL university learners selected from English Language Teaching Department of Daneshvaran University in Tabriz. Thirty EFL students from the department participated in the study. The participants were young adults and their age ranged from 19 to 25. Also, all of the students were native speakers of Turkish and Persian. They were studying English language teaching. At the time of data collection, they were in their 2nd year of university education.

In order to make sure about the homogeneity between control group and experimental group, proficiency pre-test (A standardized test by Jack C. Richard) was administered to the population of 50 . After that on the basis of the results of test only students who obtained 24 to 36 , were chosen to participate in the study. Then, they were randomly divided into two groups: one control group $(n=15)$ and experimental group $(n=15)$. This sample has been chosen in order to investigate the effect of awareness raising activities on the reading comprehension of culturally bound texts.

\subsection{Instrumentation}

Before any treatment, a placement standardized test (by Jack. C. Richards) was given to the students in order to have homogeneous groups. Then this proficiency test was administered to both groups which consisted of a listening part with 9 conversations and 20 multiple choice questions, then a reading part with some short passages and 20 multiple choice questions and finally language use part with 30 multiple choice questions.

To meet the objectives of the study, five cultural texts were. All were about the holidays, costumes and ceremonies of foreign countries. Culture specific texts were about Halloween Day, Easter Day, April fool's Day, and ... which all of them relate to foreign celebrations and reflect their culture. Also twenty comprehension questions in multiple- choice form were taken from Internet and Jack. C, Richard's book. The reason behind the use of multiple-choice questions was the objectivity of this form of questions.

\subsection{Procedure}

The pre-test contains 70 multiple choice questions, including_ Listening (20 items), Reading (20 items), and language use (30 items) _ and requires 50 minutes to administer. Also, considered scores were 24 to 36 , so all the students who obtained these scores could participate in the research. The participants were tested in their own classes as part of their regular classroom activity. After the placement test they were randomly divided in to two groups_Experimental group (E.G) and Control group (C.G). Both groups were provided with the five culture- specific passages of Halloween's Day, April fool's Day, Saint Patrick's Day, and Easter Day and Valentine's Day in frequent sections. For C.G, no pre- reading activities were included, but in E.G we had awareness raising activities, such as pre-teaching new vocabularies, using pictorial contexts, and also a list of key words and specific words were written on the board and contextualized in the frame work of some sample sentences. Finally, after they read the texts, they were given 20 multiple-choice reading comprehension questions. The papers were corrected and the results were analyzed by using T-test method.

\section{Results}

In order to determine if the two conditions have about the same or different amounts of variability between scores, we did the independent sample test which is shown in following table:

Table 1. Independent Samples Test 


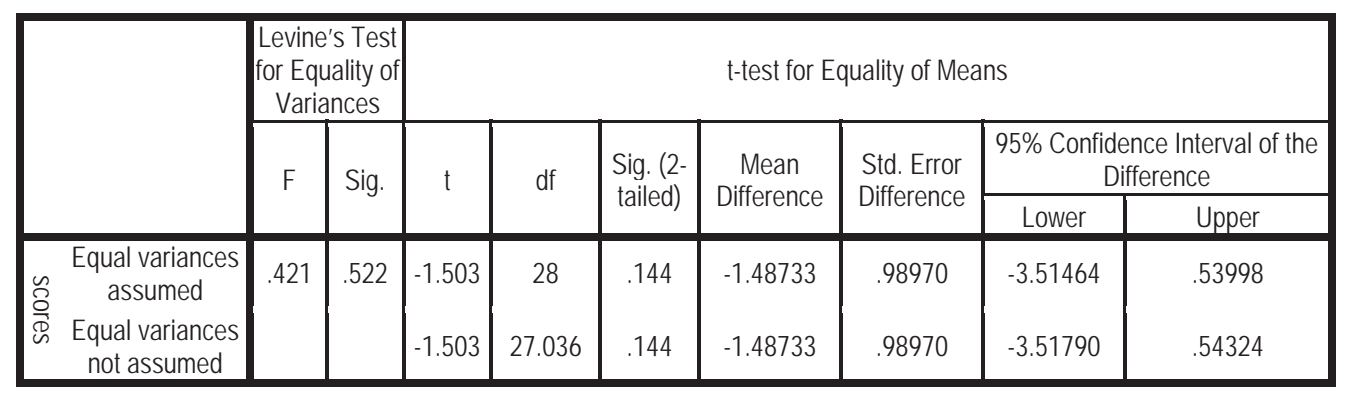

Having a look on the means and comparing them, shows that there is no important difference between the two groups. Although the low scores and means present that the pre-test was probably too difficult for them.

\subsection{Post- test (Data Analysis and Results)}

In this part all the results of the post-test of two groups will be analyzed. The raw scores obtained by the experimental and the control groups are shown in table 2. Also means and standard deviations of two groups on the post-test are presented in table 3.

Table 2. The Raw Scores Obtained by the Experimental and Control Groups on the Post-Test

\begin{tabular}{|c|c|c|c|}
\hline \multicolumn{2}{|c|}{ Experimental Group } & \multicolumn{2}{c|}{ Control Group } \\
\hline No & Score & No & Score \\
\hline 1 & 11.00 & 1 & 11.00 \\
\hline 2 & 13.00 & 2 & 11.00 \\
\hline 3 & 14.00 & 3 & 11.00 \\
\hline 4 & 16.00 & 4 & 13.00 \\
\hline 5 & 16.00 & 5 & 13.00 \\
\hline 6 & 16.00 & 6 & 13.00 \\
\hline 7 & 16.00 & 7 & 14.00 \\
\hline 8 & 17.00 & 8 & 14.00 \\
\hline 9 & 17.00 & 9 & 15.00 \\
\hline 10 & 18.00 & 10 & 15.00 \\
\hline 11 & 18.00 & 11 & 16.00 \\
\hline 12 & 18.00 & 12 & 17.00 \\
\hline 13 & 19.00 & 13 & 17.00 \\
\hline 14 & 19.00 & 14 & 18.00 \\
\hline 15 & 20.00 & 15 & 19.00 \\
\hline
\end{tabular}

Table 3. Means and Standard Deviation of Two Groups on the Post-Test

\begin{tabular}{|cc|c|c|c|c|}
\hline & group & $\mathrm{N}$ & Mean & Std. Deviation & Std. Error Mean \\
\hline \multirow{2}{*}{ post_test } & experimental-g & 15 & 16.5333 & 2.41622 & .62386 \\
& control-g & 15 & 14.4667 & 2.55976 & .66093 \\
\hline
\end{tabular}

It illustrates the differences between the means of scores obtained by the control and the experimental groups on the post-test.

Comparing the means of two groups shows that the performance of experimental group is better than the control group on the post-test.

Figure 1. Comparison of the Means of Two Groups on the Post-test 


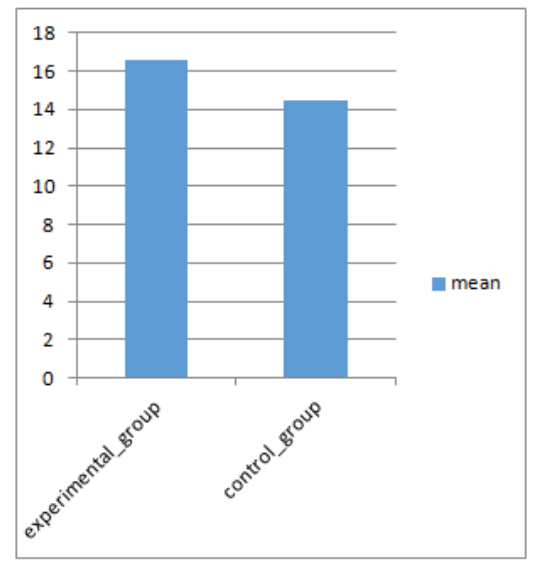

Table 4. Independent Samples Test

\begin{tabular}{|c|c|c|c|c|c|c|c|c|c|}
\hline & \multicolumn{2}{|c|}{$\begin{array}{l}\text { Levene's Test for } \\
\text { Equality of } \\
\text { Variances }\end{array}$} & \multicolumn{7}{|c|}{ t-test for Equality of Means } \\
\hline & \multirow[t]{2}{*}{$\mathrm{F}$} & \multirow[t]{2}{*}{ Sig. } & \multirow[t]{2}{*}{$\mathrm{t}$} & \multirow[t]{2}{*}{ Df } & \multirow{2}{*}{$\begin{array}{l}\text { Sig. (2- } \\
\text { tailed) }\end{array}$} & \multirow{2}{*}{$\begin{array}{c}\text { Mean } \\
\text { Difference }\end{array}$} & \multirow{2}{*}{$\begin{array}{l}\text { Std. Error } \\
\text { Difference }\end{array}$} & \multicolumn{2}{|c|}{$\begin{array}{c}95 \% \text { Confidence Interval } \\
\text { of the Difference }\end{array}$} \\
\hline & & & & & & & & Lower & Upper \\
\hline 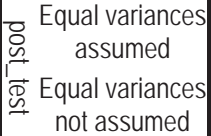 & .261 & .613 & $\begin{array}{r}2.274 \\
2.274\end{array}$ & $\begin{array}{c}28 \\
27.907\end{array}$ & $\begin{array}{l}.031 \\
.031\end{array}$ & $\begin{array}{l}2.06667 \\
2.06667\end{array}$ & $\begin{array}{l}.90886 \\
.90886\end{array}$ & $\begin{array}{l}.20495 \\
.20467\end{array}$ & $\begin{array}{l}3.92839 \\
3.92867\end{array}$ \\
\hline
\end{tabular}

According to the aim of the research which is investigating the effect of awareness raising on reading comprehension of culturally-bound materials, we expect a high significant difference between the control and the experimental groups after the treatment. By using the t-test the difference between the two means was computed. As it is routine, if the Sig (2Tailed) value is less than or equal to $.05 \ldots$ we can conclude that there is a statistically significant difference between our two conditions. According to the results of the post-test illustrated in table IV, P value is 0.031 and it is less than 0.05 ( $P$ 0.05), this smaller $\mathrm{p}$-value shows stronger evidence against $\mathrm{H} 1$. This result implies that first hypothesis is rejected and second hypothesis is approved, it means awareness raising activities have positive effect on the L2 learners reading comprehension of culturally-bound materials. The results clearly show that the treatment was effective to make an important difference between the experimental and the control group.

\section{Discussion}

The current study examined the effect of awareness raising activities on reading comprehension of culturally bound materials. In this section, the results obtained from data analysis are discussed and presented in a way that addresses null-hypothesis presented earlier.

With regard to the null-hypothesis, awareness raising activities don't have any effect on the L2 learners reading comprehension of culturally- bound materials, it was rejected by the results of the study. In other words, the results confirmed what has been widely acknowledged as the positive effect of background knowledge and cultural familiarity on reading comprehension. The difference between the two groups' performances in comprehension suggested a strong possibility that the students who received awareness raising activities before reading the cultural texts were more successful in comprehension rather than students who didn't have any awareness raising activities. In the experimental group, the students seemed to find it easier to allocate intentional resources to more linguistic elements and construct mental representations of the familiar context. In contrast, it was much more difficult for the students to create mental representations of the unfamiliar context. Numerous authors (Kramsch, 1993, 1998; Harmer, 2001) have highlighted the 
impossibility of comprehension of a text without feed backing its receptive culture. Accordingly, the results of the present study can be a support for previous findings that reading culturally relevant texts is beneficial to student performance that is notably in accordance with what has been found in studies such as Conrad et al 2004; McCollin \& O'Shea, 2005; Pinkard, 2001; Zolbrod, 2006, all cited in McCullough, 2008. Thus, it is beneficial to recommend that a high level of culturally bound prior knowledge supports students' reading comprehension. Although the awareness raising activities can't cause understanding of everything, they can be helpful in comprehension of whole text, which is the primary aim of reading teaching.

These results are also in line with those of the studies conducted by Mueller (1980), O'Malley and Chamot (1989), Long (1990), Sadighi and Zare (2002), who found that cultural background knowledge plays an important role in interpreting meaning, as this forms a foundation for readers to connect new information to their existing knowledge. Raising awareness leads to a sizeable improvement in the degree of the motivation of language learners in their more efficient performance on reading comprehension texts. The same effect has been proved by experts like Gardner and Lambert (1959 \& 1965). They all agreed on the point that in achieving high motivation, classes involving culturally-based activities such as vocabulary pre-teaching, doing research on countries and people and using photos do have a great effect. Considering cultural awareness by means of nativazation, the findings in studies such as Alptekin (2006); Jalilifar \& Assi, (2008) can be a support for what is found in this study as nativization is a kind of cultural awareness.

\section{Conclusion}

By way of conclusion, we should reiterate the main premise of the present study: awareness raising activities has positive effect on the L2 learners reading comprehension. The importance of investigating the effect of awareness raising activities on reading comprehension increases when the text contains a significant amount of cultural knowledge. When the text includes languages, phrases, expressions and historical facts from different ethnic groups, equal prior knowledge cannot be assumed. Because culturally bound prior knowledge is strongly associated with comprehension, so giving related background knowledge increases student's cultural knowledge of their own, and different racial and ethnic groups and also it could be beneficial for their reading comprehension performance.

The significant correlation between the awareness raising activities and the results of the post-test for the entire sample provide evidence that the higher a learner's cultural awareness, the higher comprehension of a cultural text. The results corroborate and verify the hypothesis that awareness raising activities facilitate reading comprehension of culturally-bound materials. So, the results of post-test support the hypothesis 2 demonstrated that an increase in the level of cultural awareness is concomitant with an increase in reading comprehension. The significant result of this research provides support for looking at culturally-bound prior knowledge as a cognitive tool that can be used to structure more effective learning tasks, so the teachers can use them in teaching reading comprehension in L2 classrooms. During the research, in order to activate the students' own experience and schematic knowledge extra attention was on the prereading activities. The schematic knowledge ease restoring some of the original reception conditions of the text and causes the students to receive it in a similar way. These activities can make the use of a text more authentic; also make learners aware of the fact that comprehension of a text doesn't mean understanding the whole text but using some suitable strategies for more comprehension.

Regarding suggestions for further research, the results of the present study are on the base of just five cultural texts about different ceremonies. Therefore, it requires further studies regarding other fields of culture. Another significant area is that "how" culture-specific points should be taught in classrooms.

\section{References}

Alptekin, C. (2006). Cultural familiarity in inferential and literal comprehension in L2 reading. System, 34, 494-508.

Bock, T. (2006). A consideration of culture in moral theme comprehension: Comparing Native and European American students. Journal of Moral Education, 35, 71-87.

Carrell, P. L. (1984). Evidence of a formal schema in second language comprehension. Language Learning, 34, pp.1-31.

Chastain, K. (1988). Developing second language skills: Theory and practice: Orlando, Florida: HBT.

Ellis, S.R. (1993). Pictorial Communication in Virtual and real environment, New York: Taylor \& Frana.

Erten,I.H., Razi, S. (2009). The effects of cultural familiarity on reading comprehension. Çanakkale Onsekiz Mart University, Turkey.

Gardner RC, Lambert WE (1959). Motivational variables in second language acquisition. Canadian Journal of Psychology, 13: 266-272.

Gardner RC, Lambert WE (1965). Language aptitude, intelligence, and second language achievement. Journal of Educational Psychology, 56: 191-199.

Harmer, J. (2001). The Practice of English Language Teaching. ESSEX: Pearson Education Limited. 
Jalilifar, A. \& Assi, R. (2008). The Role of Cultural Nativization in Comprehension of Short Stories in EFL Reading Contexts. The International Journal of Language Society and Culture.

Kohonen, V. (1991). Foreign Language Learning as Learner Education: Facilitating Self-Direction in Language Learning. Transparency and Coherence in Language Learning in Europe. Council for Cultural Cooperation, Switzerland.

Kramsch, C. (1993). Context and Culture in Language Teaching. Oxford: Oxford University Press.

Kramsch, C. (1998). Language and culture. Oxford: Oxford University Press.

Long, D. R. (1990). What you don't know can't help you: An exploratory study of background knowledge and second language listening comprehension. Studies in Second Language Acquisition, 12, 65-80.

McCullough, R.G. (2008). The Influence of Culturally Bound Prior Knowledge on Comprehension Performance. Loyola University of Chicago.

Mueller, G. A. (1980). Visual contextual cues and listening comprehension: An experiment. Modern Language Journal, 64, 335-340.

O'Malley JM, Chamot AU, (1989). Listening comprehension strategies in second language acquisition. Applied Linguistics, 10(4): 418437.

Pulido, D. (2004). The Effects of Cultural Familiarity on Incidental Vocabulary Acquisition Through Reading. The Reading Matrix, 4(2), 20-53.

Rivers, W. (1981). Teaching foreign language skills (2nd ed.). Chicago: University of Chicago Press.

Sadighi, F. \& Zare, S. (2002). Is listening comprehension influenced by the background knowledge of the learners? A case study of Iranian EFL learners. The linguistics Journal, 1(3), 110-126.

Sasaki, M. (2000). Effects of cultural schemata on students' test taking processes for cloze tests: A multiple data source approach. Language Testing, 17(1), 85-114.

Steffensen, M. S. ,Joag-Dev, C., \& Anderson, R. C. (1984). A cross-cultural perspective on reading comprehension. Reading Research Quarterly, 15, 10-29.

Taglieber, L.K., Johnson, L.L. and Yarbrough, D.B. (1988). Effects of pre-reading activities on EFL reading by Brazillian college students. TESOL Quarterly 22: 455-472.

Twist, L., Gnaldi, M., Schagen, I.; and Morrison, J. (2004). Good Readers but at a Cost? Attitudes towards reading in England. Journal of Reading Research in Reading, 27:387-400.

Urquhart, S., Weir,C. (1988). Reading in a Foreign Language: Process, Product and Practice. New York: Longman.

Wolfram,W. (1998). Dialect awareness and the study of language in Egan- Roberson \& Bloom (Eds): University of Hawaii. 